\title{
Use of actively cooled and activated coolant for surface quality improvement in ductile material grinding
}

\section{Y. Gao and H. Lai}

Department of Mechanical Engineering, Hong Kong University of Science and Technology, Clear Water Bay, Kowloon, Hong Kong SAR, China.

Email: meygao@ust.hk (Y. Gao).

\begin{abstract}
An active cooling and activation approach for coolant during ductile material grinding is proposed and examined. The aim is to enhance the surface quality of the workpiece being machined by the grinding process. Problems in the existing cooling approaches, such as activation, cryogenic cooling, and chilled air cooling, are discussed. Experimental and computational studies of the effects of actively cooled and activated coolant for ductile material grinding were conducted. Experimental results show that the proposed approach is able to improve surface quality by up to $36.68 \%$ on average in terms of surface roughness $R_{\mathrm{a}}$. In addition, it was found that surface roughness could be reduced if the coolant temperature is reduced. The results of the XRD tests show that the proposed method could, in general, produce low residual stress values. Further studies of this topic are necessary. Results of optical and SEM examinations also confirmed that the proposed approach is advantageous.
\end{abstract}

Keywords: active cooling, activated coolant, grinding, surface roughness, residual stress.

Biographical notes: Y. Gao received his PhD degree from the University of Birmingham, UK, in 1992. His research interests include micro fabrication, nano precision machining, and in-process optical measurement.

H. Lai is in the process to receive his MPhil degree from the Hong Kong University of Science and Technology in 2006. He is now a $\mathrm{PhD}$ research student pursuing research in precision machining, in particular, grinding.

\section{Introduction}

Heat generated in grinding could cause thermal deformation in grinding wheel and workpiece. This could affect the machining accuracy during a grinding process (Ramesh et al. 2004; Wang and Kou 1998). Heat effects can be reduced by use of coolant to be applied between the wheel and the workpiece (Wang and Kou 1997). However, the process of heat conduction by coolant would need a long period of time to achieve an equilibrium state (Gao et al. 2003). Prior to the equilibrium state, the coolant temperature would continuously increase, which will seriously affect the accuracy of the machining process and make the production output unstable (Choi et al. 2001).

Megasonic coolant can excite the coolant which will infiltrate more efficiently into the grinding zone to provide better cooling (Suzuki et al. 2004; 2003). Improvement in surface roughness of ductile material by $20-30 \%$ can be obtained and wheel wear was reduced. The problem of continuous increase in coolant temperature will remain.

Cryogenic cooling can rapidly take heat away from the grinding zone. However, a significant temperature gradient, as large as $100^{\circ} \mathrm{C}$, could be generated by the fast cooling action. This could cause excessive thermal stresses on the workpiece surface (Tsai and Hocheng 1998). This is undesirable and could affect the machining accuracy. In addition, frequent replenishment of liquid nitrogen is costly and it requires great care for safety 
Author

(Paul and Chattopadhyay 1995; 1995; 1996). The cooling air approach could cause strong noises as the delivery speed is very high (Ramesh et al. 2003; Choi et al. 2002).

In order to address the above problems, an actively cooled and activated coolant approach is proposed and the working principle is introduced. Experimental and computational studies of the effects of actively cooled and activated coolant for ductile material grinding were conducted to assess the proposed method. The grinding wheel speed was determined by a number of experimental tests. Different values in depth of cut, feedrate and coolant temperature were applied. The machined workpieces were examined using an optical profiler, a microscope, and an instrument for SEM for characterization. Experimental results show that the use of actively cooled and activated coolant is able to improve the surface quality by up to $36.68 \%$ on average in terms of surface roughness $R_{\mathrm{a}}$.

\section{Use of actively cooled and activated coolant}

A cooling and activation system will be used to deal with the coolant used for precision grinding. The system is based on forced convection of heat generated during the machining process and high frequency activation was applied. A compact heat pump and nozzle were used. The coolant temperature, noted as $t_{\mathrm{c}}$, could be reduced to approximately $2^{\circ} \mathrm{C}$ under no load condition, and to approximately $9^{\circ} \mathrm{C}$ under loading. The cooling tank capacity was 25 l. The working principle is illustrated in Fig. 1.

Figure 1 Active cooling and activation system

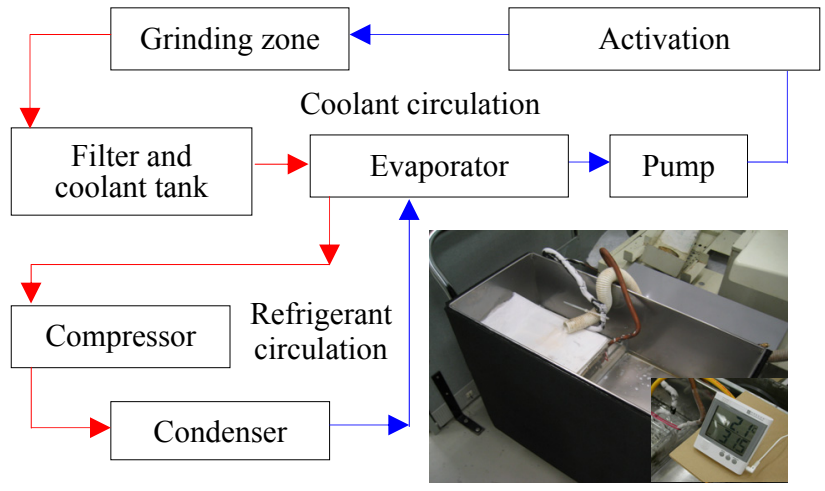

\section{Computational testing for cooled and activated coolant}

Computational testing for cooling and activation effects was conducted to examine the temperature reduction through the use of the cooled and activated coolant (Fig. 2) (Gao and Lai 2005). The grinding length $l=\left(d_{\mathrm{c}} D\right)^{1 / 2}$ (Wang and Kou 1998), where $d_{\mathrm{c}}$ is the depth of cut. In the model (Fig. 2), the heat is assumed to be uniformly distributed over the contact region and is given as $q=F_{\mathrm{t}} v_{\mathrm{s}} / l b$ (Wang and Kou 1998), where $b$ is the width of the grinding wheel, $F_{\mathrm{t}}$ is the tangential grinding force, and $v_{\mathrm{s}}$ is the grinding wheel velocity. The heat being taken away by the coolant is given as $q_{\mathrm{c}}=\left(1-R_{\mathrm{c}}\right) R_{\mathrm{Qw}} q /(1-r)$ (Wang and Kou 1998), where $r$ is the wear flat ratio, $R_{\mathrm{c}}$ is the ratio of heat in workpiece which is related to the effectiveness of the coolant, and $R_{\mathrm{Qw}}$ is the fraction of heat into the workpiece at the wear flat area. To avoid the complexity in activation modeling, the activation effects are lumped into $q_{\mathrm{c}}$, noted as $q_{\mathrm{ac}}=\left(1-R_{\mathrm{ac}}\right) R_{\mathrm{Qwa}} q /(1-r)$ (Table 1$)$. In addition, the model was simplified to be without details of fluid through the grinding zone (Hryniewwicz et al. 2000; Ramesh et al. 2001; Jin et al. 2003; Gviniashvili et al. 2004). In the computational testing, the heat was generated for $\Delta t=1 \mathrm{~s}$ and was then taken 
away from the grinding zone (Fig. 2 and Table 1). Totally five cases were examined to investigate the heat generation and heat transfer process (Table 2 and Fig. 3), where $v_{\mathrm{c}}$ is the coolant velocity. From Table 2 and Fig. 3, it can be seen that the maximum and the average temperatures in the grinding zone, noted as $t_{\text {gmax }}$ and $t_{\text {gavg }}$ (Fig. 2 and Table 2), respectively, can be reduced when using the proposed approach.

Table 1 Conditions for computational testing

\begin{tabular}{ll}
\hline Analysis device & CPU: P4 2.2GHz, 2GB RAM \\
\hline \multirow{2}{*}{ Software } & Solid model: SolidWorks 2004 \\
& Fluid analysis: ANSYS CFX 10 \\
\hline \multirow{2}{*}{ Physical properties type } & Workpiece: Steel \\
& Fluid: Water and air \\
\hline \multirow{2}{*}{ Fluid models } & Heat transfer model: Thermal energy \\
& Turbulence model: Shear stress transport \\
\hline & Depth of cut: $d_{\mathrm{c}}=5 \mu \mathrm{m}$, Grinding length: $l=0.9354 \mathrm{~mm}$ \\
& Grinding wheel diameter: $D=175 \mathrm{~mm}$ \\
& Grinding wheel width: $b=6 \mathrm{~mm}$ \\
& Grinding wheel speed: $n_{\mathrm{s}}=2600 \mathrm{rpm}$ \\
& Grinding wheel velocity $v_{\mathrm{s}}=23.82 \mathrm{~m} / \mathrm{s}$ \\
& Wear flat ratio: $r=0.5$ \\
& Fraction of heat into workpiece: $R_{\mathrm{Qw}}=0.5$ \\
& Fraction of heat into workpiece under activation: $R_{\mathrm{Qwa}}=0.45$ \\
& Ratio of heat in workpiece: $R_{\mathrm{c}}=0.95$ \\
& Ratio of heat in workpiece under activation: $R_{\mathrm{ac}}=0.924$ \\
& Heat removal increment due to activation: $\Delta q_{\mathrm{c}}=36.68 \%$ \\
& Heat removal: $q_{\mathrm{c}}=6.36^{*} 10^{6} \mathrm{~W} / \mathrm{m}^{2}$ \\
& Heat removal under activation: $q_{\mathrm{ac}}=\left(1+\Delta q_{\mathrm{c}}\right) q_{\mathrm{c}}$ \\
\hline \multirow{2}{*}{ Timalysis conditions } & Physical timescale: $0.02 \mathrm{~s}$ \\
& Max. no. of iterations: 50 \\
\hline \multirow{2}{*}{ Mesh statistics } & Number of nodes: 16869 \\
& Number of elements: 87528 \\
& Element: Tetrahedral type \\
\hline
\end{tabular}

Figure 2 Models for computation testing
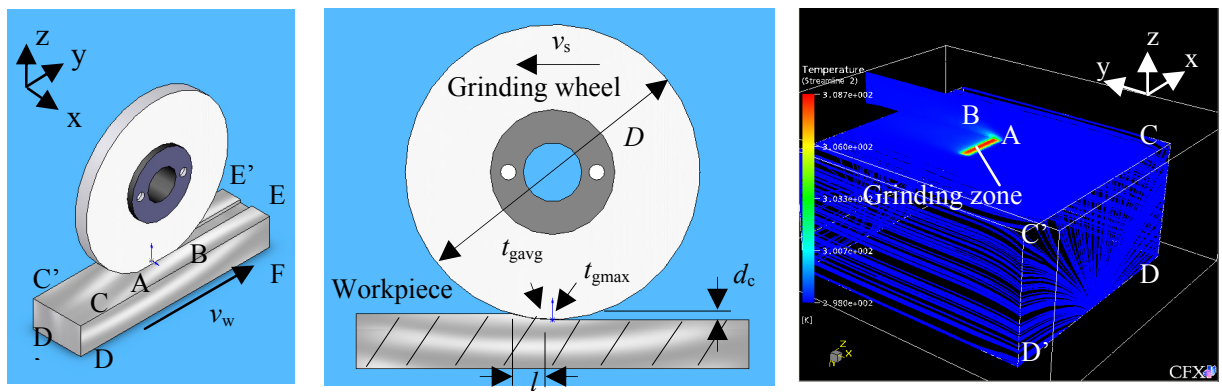

\section{Experimental results and discussion}

To validate the proposed method, a number of experimental tests were conducted and comparison made. Effects of workpiece table speed $v_{\mathrm{w}}$ and depth of cut $d_{\mathrm{c}}$ on the response variables such as surface roughness, surface morphology, and sub surface residual stress were studied under the condition of normal coolant and actively cooled and actuated coolant. Totally, 40 tests (Table 3) were conducted. For $d_{\mathrm{c}}$ tests, 20 grinding trials were conducted. The wheel feed profile was $n_{\mathrm{g}} \in[1,10]$, where $n_{\mathrm{g}}$ is the grinding 
Author

pass number, for grinding at $v_{\mathrm{w}}=80 \mathrm{~mm} / \mathrm{s}$, and $n_{\mathrm{g}} \in[1,10]$ for sparking. For $v_{\mathrm{w}}$ tests, 20 grinding trials were realized. The wheel feed profile was $n_{\mathrm{g}} \in[1,10]$ for grinding at $d_{\mathrm{c}}=1 \mu \mathrm{m}$, and $n_{\mathrm{g}} \in[1,10]$ for sparking. To minimize the wear effect of the grinding wheel, dressing was applied before each type of the grinding tests.

Table 2 Computational testing results

\begin{tabular}{lllllll}
\hline Type & $\begin{array}{l}t_{\mathrm{c}} \\
\left({ }^{\circ} \mathrm{C}\right)\end{array}$ & $\begin{array}{l}v_{\mathrm{c}} \\
(\mathrm{mm} / \mathrm{s})\end{array}$ & $\begin{array}{l}t_{\text {gmax }} \\
(\mathrm{K})\end{array}$ & $\begin{array}{l}t_{\text {gmax }} \\
\left({ }^{\circ} \mathrm{C}\right)\end{array}$ & $\begin{array}{l}t_{\text {gavg }} \\
(\mathrm{K})\end{array}$ & $\begin{array}{l}t_{\text {gavg }} \\
\left({ }^{\circ} \mathrm{C}\right)\end{array}$ \\
\hline No coolant & 25 & & 310.2 & 37.2 & 304.1 & 31.1 \\
\hline Air & 25 & 105.82 & 308.7 & 35.7 & 303.3 & 30.3 \\
\hline Normal coolant & 25 & 105.82 & 298.1 & 25.1 & 298.1 & 25.1 \\
\hline Cooled coolant & 9 & 105.82 & 282.1 & 9.1 & 282.1 & 9.1 \\
\hline $\begin{array}{l}\text { Cooled and activated } \\
\text { coolant }\end{array}$ & 9 & 105.82 & 282.076 & 9.076 & 282 & 9 \\
\hline
\end{tabular}

Figure 3 Temperature distributions on a workpiece surface
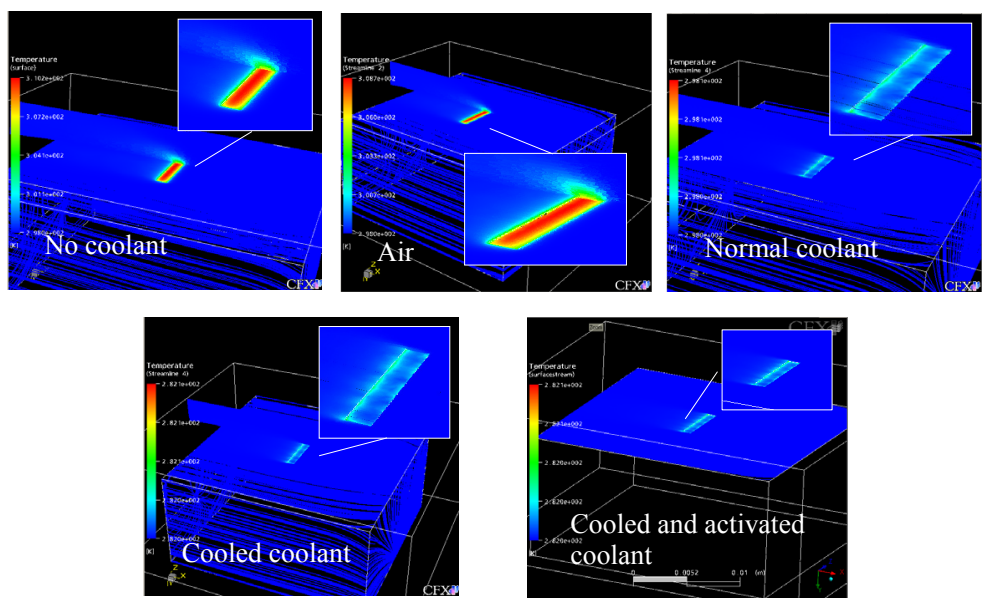

Table 3 Experimental test conditions

\begin{tabular}{ll}
\hline Workpiece & Mild steel plate $105 \mathrm{~mm} \times 25 \mathrm{~mm} \times 12 \mathrm{~mm}$ \\
\hline Grinding wheel & $\mathrm{Al}_{2} \mathrm{O}_{3}$ 91A120K5AV217 175x6x31.75mm \\
\hline Wheel speed & $n_{\mathrm{s}}=2600 \mathrm{rpm}$ \\
\hline Workpiece table speed & $v_{\mathrm{w}}=40-120 \mathrm{~mm} / \mathrm{s}$ \\
\hline Depth of cut & $d_{\mathrm{c}}=1-5 \mu \mathrm{m}$ \\
\hline Feed profile & $\begin{array}{l}\text { Grinding: } n_{\mathrm{g}} \in[1,10] \\
\text { Sparking: } n_{\mathrm{g}} \in[1,10]\end{array}$ \\
\hline Grinding fluid & Soluble type at $5 \%$ dilution, $9{ }^{\circ} \mathrm{C}, 0.81 / \mathrm{min}$ \\
\hline Grinding machine & ESG-818ASD \\
\hline
\end{tabular}

For wheel speed selection, totally five grinding tests on steel plates were conducted at the wheel speed $n_{\mathrm{s}}=1400,1700,2000,2300$, and 2600rpm, respectively. The maximum wheel speed was approximately $2880 \mathrm{rpm}$. The workpiece table speed $v_{\mathrm{w}}=80 \mathrm{~mm} / \mathrm{s}$. Based on the results of surface roughness measurement, $n_{\mathrm{s}}=2600 \mathrm{rpm}$ was found to be suitable for producing better workpiece surface quality. A Renishaw laser interferometer was used 
Title

to measure the workpiece table speed $v_{\mathrm{w}}$. A lower workpiece table speed combining with a higher grinding wheel speed would generally give better surface (Nakayama et al. 2004). The workpiece table speed was selected as $v_{\mathrm{w}}=40,60,80,100$, and $120 \mathrm{~mm} / \mathrm{s}$, respectively, for the study (Gao and Lai 2005).

The test samples were measured using a Wyko optical profiler in the vertical scanning interferometry, or VSI, mode, which has a resolution of $1 \mathrm{~nm}$. The surface roughness results in terms of $R_{\mathrm{a}}, R_{\mathrm{z}}$, and $R_{\mathrm{t}}$ or $R_{\mathrm{y}}$, respectively, are shown in Fig. 4-5 and Table 4-5. It can be seen that the surface roughness was generally reduced when the proposed method of use of cooled and activated coolant was utilized (Fig. 4-5 and Table 4-5). In addition, if $d_{\mathrm{c}}$ was increased, surface roughness would generally increase (Fig. 45). Lower table speed $v_{\mathrm{w}}$ would normally give lower roughness values (Fig. 4-5) with a few exceptions, where lower $v_{\mathrm{w}}$ did not give improvements (Fig. 5(b)-(c) and Table 5) due to increased vibrations. It is noted that the maximum $d_{\mathrm{c}}$ value was set to be less than $6 \mu \mathrm{m}$ (Table 4 and Fig. 4) to avoid a large grinding force. The measurement equipment conditions are shown in Table 6.

Table 4 Surface roughness improvement for $d_{\mathrm{c}}$ tests

\begin{tabular}{llllll|l}
\hline Depth of cut $d_{\mathrm{c}}(\mu \mathrm{m})$ & 1 & 2 & 3 & 4 & 5 & Avg. improvement \\
\hline Improvement in $R_{\mathrm{a}}(\%)$ & 38.08 & 36.43 & 39.74 & 35.10 & 34.04 & 36.68 \\
\hline Improvement in $R_{\mathrm{z}}(\%)$ & 26.50 & 36.04 & 33.33 & 21.78 & 27.68 & 29.07 \\
\hline Improvement in $R_{\mathrm{t}}(\%)$ & 22.62 & 34.03 & 30.83 & 19.18 & 24.07 & 26.15 \\
\hline
\end{tabular}

Table 5 Surface roughness improvement for $v_{\mathrm{w}}$ tests

\begin{tabular}{llllll|l}
\hline $\begin{array}{l}\text { Workpiece speed } v_{\mathrm{w}} \\
(\mathrm{mm} / \mathrm{s})\end{array}$ & 40 & 60 & 80 & 100 & 120 & Avg. improvement \\
\hline Improvement in $R_{\mathrm{a}}(\%)$ & 15.56 & 21.71 & 37.01 & 32.06 & 34.78 & 28.22 \\
\hline Improvement in $R_{\mathrm{z}}(\%)$ & -3.09 & -1.30 & 31.72 & 20.69 & 21.62 & 13.93 \\
\hline Improvement in $R_{\mathrm{t}}(\%)$ & -5.62 & -5.42 & 31.43 & 15.43 & 19.14 & 10.99 \\
\hline
\end{tabular}

Table 6 Measurement equipment and conditions

\begin{tabular}{ll}
\hline Olympus optical microscope & Magnification 800x \\
\hline JSM SEM & Magnification 2500x \\
\hline Wyko optical profiler & Magnification 75x \\
& Measurement area $816.5 \times 621.4 \mu \mathrm{m}$
\end{tabular}

Results of the workpiece surface inspection (Table 6) for typical $d_{\mathrm{c}}$ and $v_{\mathrm{w}}$ values and 2 coolant conditions are shown in Fig. 6-9. From Fig. 6, it can be seen that, when using normal coolant in the depth of cut test, the grinding marks are significant in the grinding direction (Fig. 6(a) and Fig. 6(c)). There are spots of peak and valley on the sample surface (Fig. 6(a)). From Fig. 7, it can be seen that, when the proposed method was applied, not only the grinding marks are less significant and there are larger flat regions (Fig. 7(c)). There are less and smaller spots of peak and valley distributed over the sample surface (Fig. 7(a)). From Fig. 8, when normal coolant was applied in the table speed test, the grinding marks remained along the grinding direction (Fig. 8(c)). There are also spots of peak and valley visible on the sample surface (Fig. 8(a) and Fig. 8(c)). The spots of peak and valley are relatively smaller when Fig. 8(c) is compared with Fig. 6(c). From Fig. 9, when using the proposed method, the spots of peak and valley and grinding marks are smaller and less significant which provided larger flat regions (Fig. 9(a) and Fig 9(c)). The advantage of the proposed method is confirmed (Fig. 6-9) as found in the grinding test (Fig. 4-5 and Table 4-5) (Gao and Lai 2005). 
Author

Figure 4 Effects of $d_{\mathrm{c}}$ on $R_{\mathrm{a}}, R_{\mathrm{z}}$ and $R_{\mathrm{t}}$

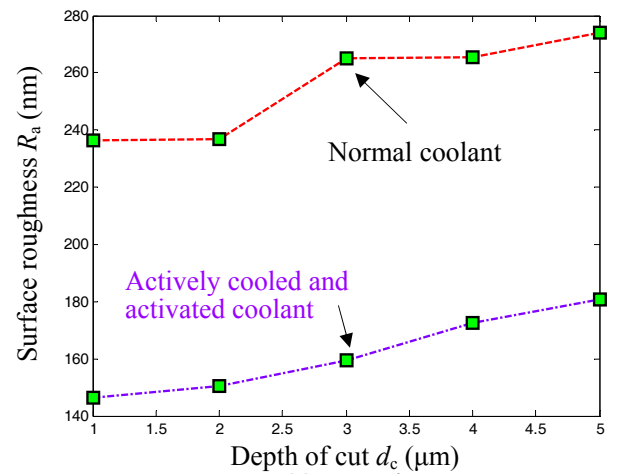

(a) $R_{\mathrm{a}}$ vs $d_{\mathrm{c}}$

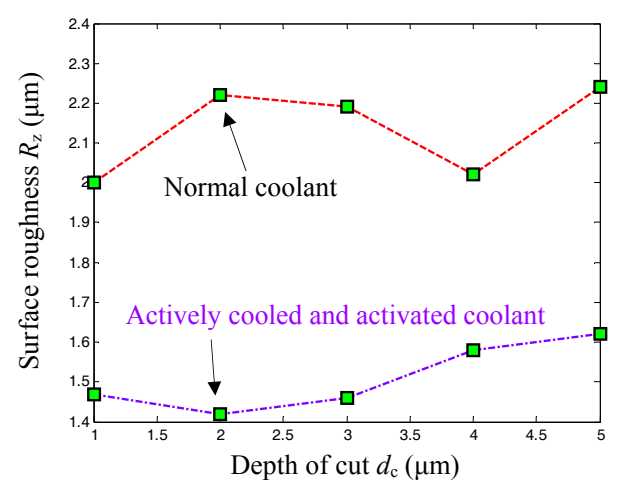

(b) $R_{\mathrm{z}}$ vs $d_{\mathrm{c}}$

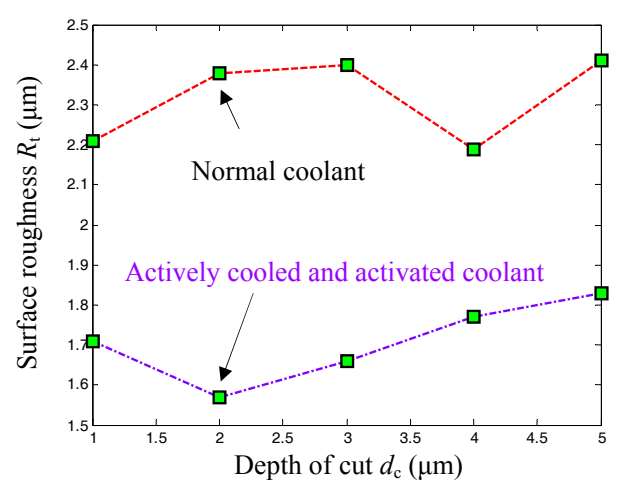

(c) $R_{\mathrm{t}}$ vs $d_{\mathrm{c}}$
Figure 5 Effects of $v_{\mathrm{w}}$ on $R_{\mathrm{a}}, R_{\mathrm{z}}$ and $R_{\mathrm{t}}$

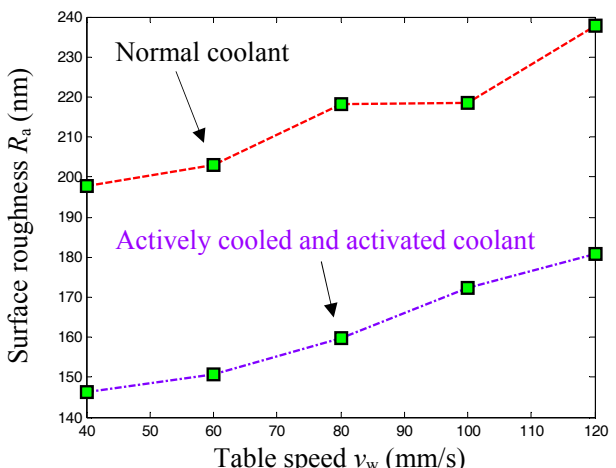

(a) $R_{\mathrm{a}} \mathrm{vs} v_{\mathrm{w}}$

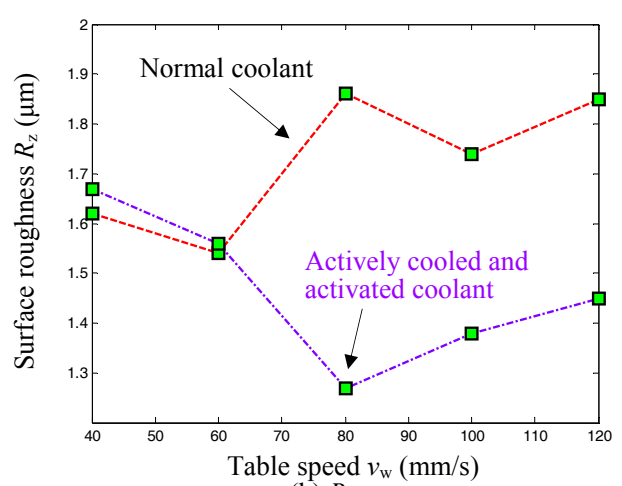

(b) $R_{\mathrm{z}} \mathrm{vS} v_{\mathrm{w}}$

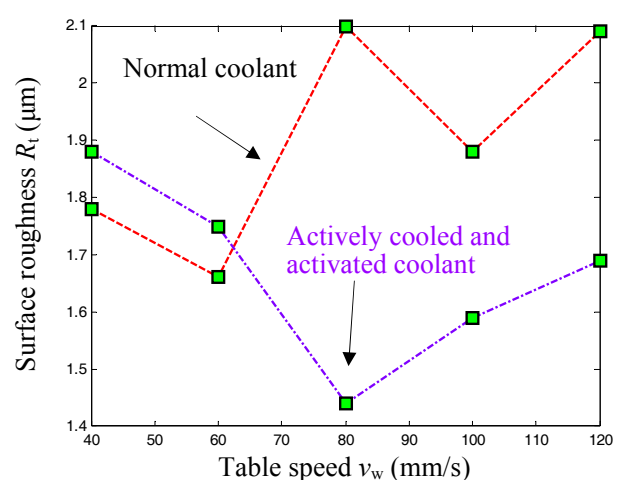

(c) $R_{\mathrm{t}}$ vs $v_{\mathrm{w}}$

A number of samples used in the depth of cut and table speed tests under 4 coolant conditions were examined by using X-ray diffraction for residual stress assessment (Table 7). Results of the X-ray diffraction measurement at a typical scanning depth of $z_{\mathrm{sc}}=-10 \mu \mathrm{m}$ are shown in Fig. 10 and Table 8. For the depth of cut test, where $d_{\mathrm{c}}=5 \mu \mathrm{m}$ and $v_{\mathrm{w}}=80 \mathrm{~mm} / \mathrm{s}$, it can be seen that an average residual stress of $\sigma_{\mathrm{zsc}}=-311.825 \mathrm{MPa}$ was obtained (Fig. 10 and Table 8 ). For the table speed test, where $d_{\mathrm{c}}=1 \mu \mathrm{m}$ and $v_{\mathrm{w}}=120 \mathrm{~mm} / \mathrm{s}$, an average residual stress of $\sigma_{\mathrm{zsc}}=-228.325 \mathrm{MPa}$ was obtained (Fig. 10 and Table 8). The 
Title

difference between the two sets of data is $83.5 \mathrm{MPa}$ (Table 8). This was jointly contributed by $d_{\mathrm{c}}$ and $v_{\mathrm{w}}$, but it may be mainly due to the much reduced depth of cut (Fig. 10 and Table 8 ).

Figure 6 Results of using normal coolant in a $d_{\mathrm{c}}$ test

(a) Optical microscope image

(b) Optical profile 3D image

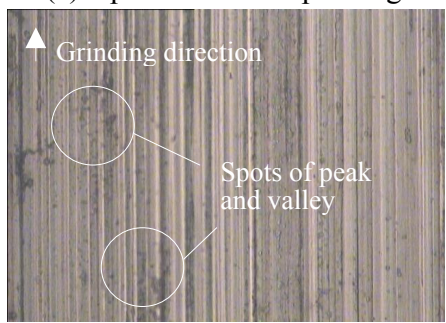

(c) SEM image

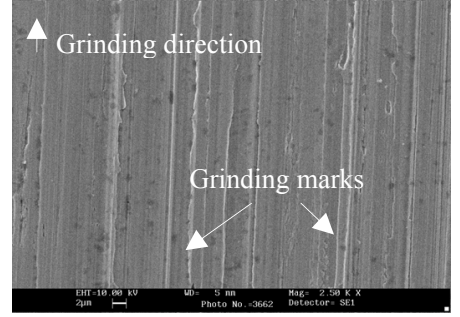

Figure 7 Results of using the proposed method in a $d_{\mathrm{c}}$ test

(a) Optical microscope image

(b) Optical profile 3D image
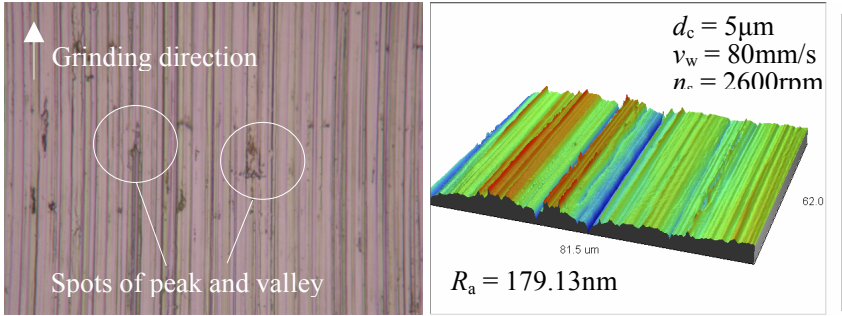

(c) SEM image

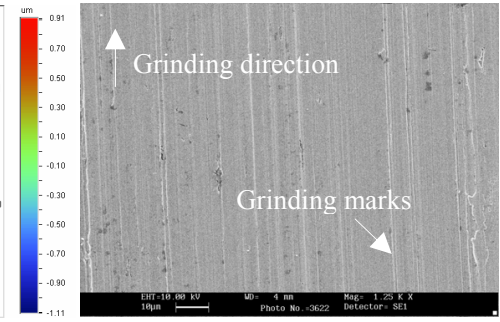

Figure 8 Results of using normal coolant in a $v_{\mathrm{w}}$ test

(a) Optical microscope image

(b) Optical profile 3D image

(c) SEM image
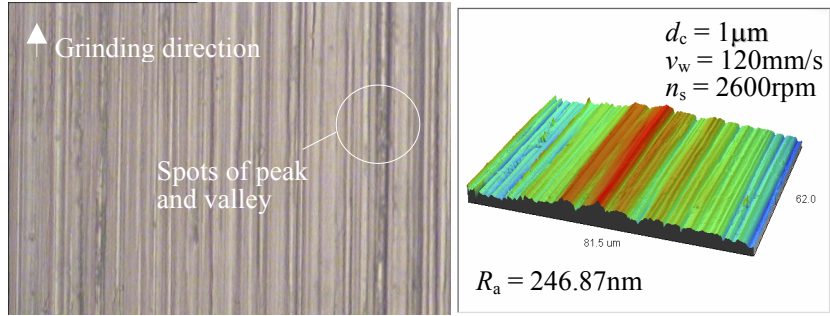

$R_{\mathrm{a}}=246.87 \mathrm{~nm}$

Figure 9 Results of the proposed method in a $v_{\mathrm{w}}$ test

(a) Optical microscope image

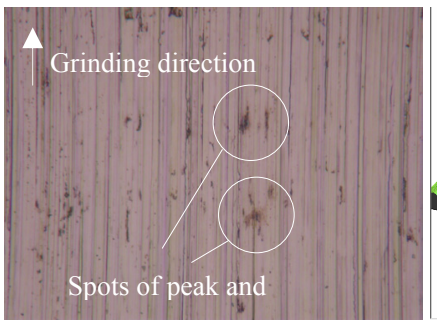

(b) Optical profile 3D image

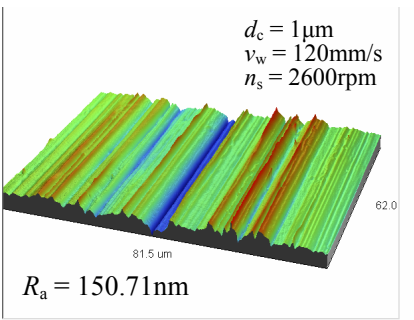

(c) SEM image

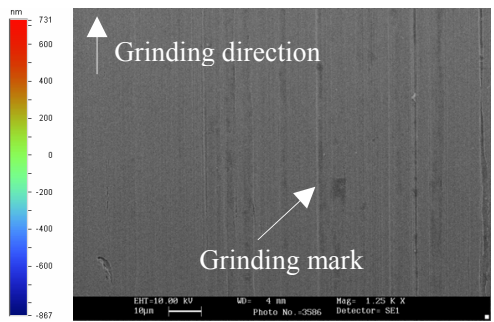


For the $d_{\mathrm{c}}$ test, it can be seen that the proposed method delivered the lowest residual stress (Fig. 10 and Table 7-8). Activation seems produce lower residual stress values and a joint action of active cooling (Gao and Lai 2005) and activation produced better results (Table 8). However, in the $d_{\mathrm{c}}$ test, the result of active cooling alone produced a higher residual stress value (Fig. 10 and Table 8). This would require further study of the approach of active cooling alone. For the $v_{\mathrm{w}}$ test, the residual stress values are similar for the normal and cooled coolant conditions (Fig. 10 and Table 7-8). The joint action of cooling and activation produced better result (Table 8). This shows that the proposed method is advantageous compared to the approach of activation alone. However, in the $v_{\mathrm{w}}$ test, it seemed that the activation produced higher residual stress values (Fig. 10 and Table 8). This would again require further study of the technique.

Table 7 XRD residual stress test conditions

\begin{tabular}{llll}
\hline Test & Coolant conditions & $\begin{array}{l}\text { Depth of cut } d_{\mathrm{c}} \\
(\mu \mathrm{m})\end{array}$ & $\begin{array}{l}\text { Table speed } v_{\mathrm{w}} \\
(\mathrm{mm} / \mathrm{s})\end{array}$ \\
\hline Depth of cut test & $\begin{array}{l}\text { Normal coolant } \\
\text { Cooled coolant } \\
\text { Activated coolant } \\
\text { Cooled and activated coolant }\end{array}$ & 5 & 80 \\
\hline Table speed test & $\begin{array}{l}\text { Normal coolant } \\
\text { Cooled coolant } \\
\text { Activated coolant } \\
\text { Cooled and activated coolant }\end{array}$ & 1 & 120 \\
\hline
\end{tabular}

Table 8 Results of the XRD tests

\begin{tabular}{l|llll|l}
\hline & Residual & stress & $\sigma_{\mathrm{zsc}}$ & $(\mathrm{MPa})$ & $\begin{array}{l}\text { Avg. value } \\
(\mathrm{MPa})\end{array}$ \\
\hline & $\begin{array}{l}\text { Normal } \\
\text { coolant }\end{array}$ & $\begin{array}{l}\text { Cooled } \\
\text { coolant }\end{array}$ & $\begin{array}{l}\text { Activated } \\
\text { coolant }\end{array}$ & $\begin{array}{l}\text { Cooled and } \\
\text { activated } \\
\text { coolant }\end{array}$ & \\
\hline Depth of cut $d_{\mathrm{c}}$ test & -324.2 & -338.95 & -308.4 & -275.75 & -311.825 \\
Table speed $v_{\mathrm{w}}$ test & -208.75 & -201.85 & -263.8 & -238.9 & -228.325 \\
\hline
\end{tabular}

To examine the effect of cooling temperature variation, further experimental tests were conducted (Table 9). A number of coolant temperature $t_{\mathrm{c}}$ values were selected. $t_{\mathrm{c}} \in\left[9^{\circ} \mathrm{C}, 21^{\circ} \mathrm{C}\right] . \Delta t_{\mathrm{c}}=3^{\circ} \mathrm{C}$. This means that the room temperature condition and the cooled coolant condition were included in the tests (Table 3 and Table 9). The wheel speed $n_{\mathrm{s}}=$ 2600rpm. Grinding was performed for 10 passes and sparking for 10 passes. The results are shown in Fig. 11-12.

Table 9 Variable coolant temperature test conditions

\begin{tabular}{lllll}
\hline $\begin{array}{l}\text { Experiment } \\
\text { set } n_{\mathrm{e}}\end{array}$ & $\begin{array}{l}\text { Depth of cut } \\
d_{\mathrm{c}}(\mu \mathrm{m})\end{array}$ & $\begin{array}{l}\text { Table speed } \\
v_{\mathrm{w}}(\mathrm{mm} / \mathrm{s})\end{array}$ & Coolant type & $\begin{array}{l}\text { Coolant } \\
t_{\mathrm{c}}\left({ }^{\circ} \mathrm{C}\right)\end{array}$ \\
\hline 1 & 3 & 80 & Cooled coolant & {$[21,18,15,12,9]$} \\
\hline 2 & 3 & 80 & Cooled actuating & {$[21,18,15,12,9]$} \\
\hline 3 & 1 & 120 & Cooled coolant & {$[21,18,15,12,9]$} \\
\hline 4 & 1 & 120 & Cooled actuating & {$[21,18,15,12,9]$} \\
\hline
\end{tabular}




\section{Title}

From Fig. 11-12, it can be seen that, for every $3^{\circ} \mathrm{C}$ reduction, which was the value of $\Delta t_{\mathrm{c}}$, in coolant temperature $t_{\mathrm{c}}$, approximately $5-6 \%$ improvement in surface quality was obtained in terms of surface roughness for the variable $t_{\mathrm{c}}$ tests (Table 9). This is due to a relatively steady $\partial R_{\mathrm{a}} / \partial t_{\mathrm{c}}$ being obtained (Fig. 11-12). In addition, the surface quality was improved by using the proposed approach when compared with the active cooling technique alone (Fig. 11-12).

Figure 10 Results of residual stress measurement

Residual stress $\left.\sigma\right|_{\mathrm{zsc}=-10 \mu \mathrm{m}}(\mathrm{MPa})$

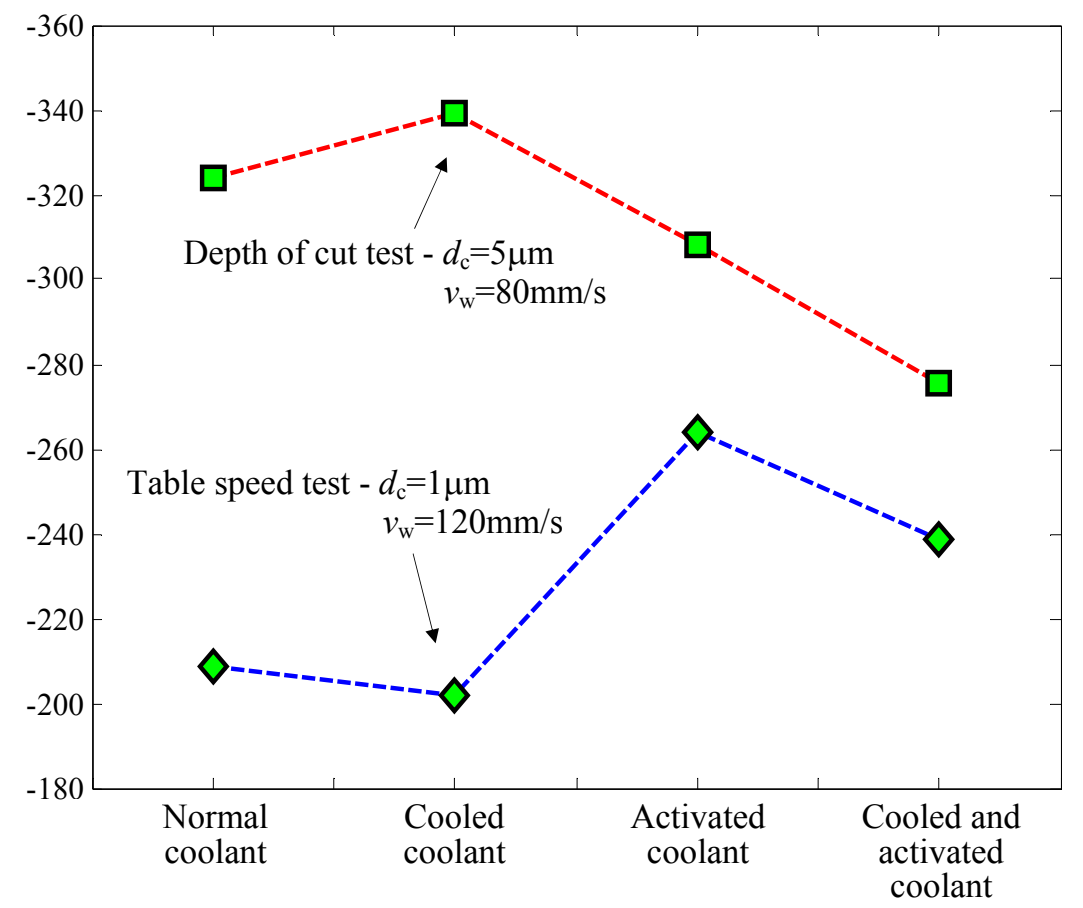

Figure $11 R_{\mathrm{a}}$ vs $t_{\mathrm{c}}$ for $n_{\mathrm{e}}=1-2$

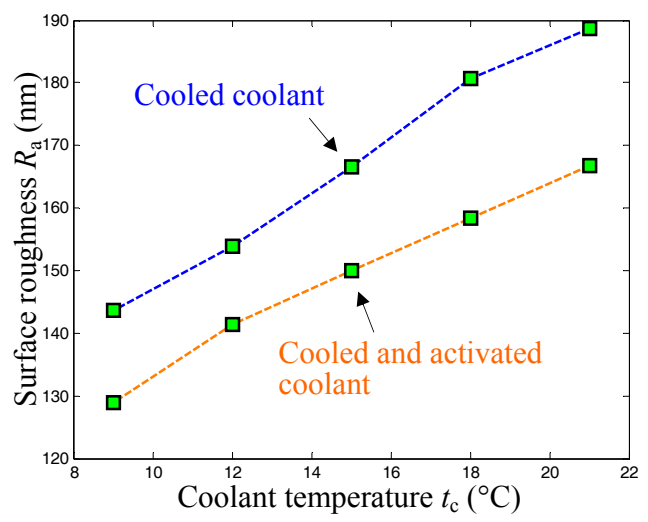

Figure $12 R_{\mathrm{a}}$ vs $t_{\mathrm{c}}$ for $n_{\mathrm{e}}=3-4$

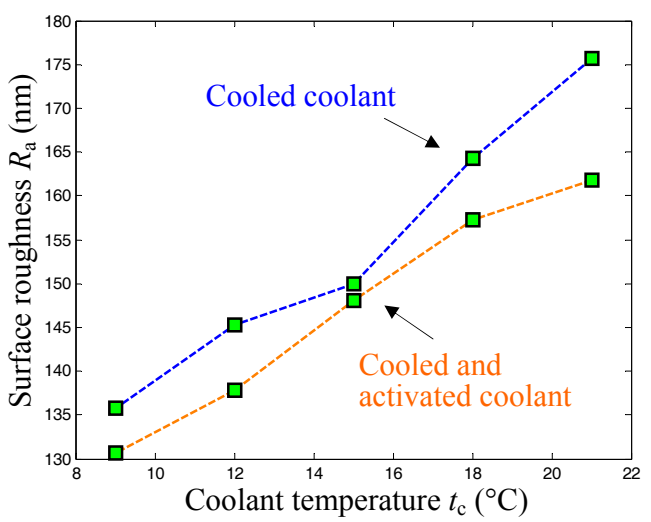


Author

\section{Conclusions}

Experimental and computational studies of the proposed approach of use of actively cooled and activated coolant for ductile material grinding were conducted. The results show that the use of the proposed approach can provide better surface quality with an average reduction up to $36.68 \%$ in surface roughness $R_{\mathrm{a}}$. For every $3^{\circ} \mathrm{C}$ reduction in coolant temperature, approximately $5-6 \%$ improvement in surface quality could be obtained in terms of surface roughness $R_{\mathrm{a}}$. In addition, the results of the optical and SEM examinations show that the machined surfaces could have significantly reduced grinding marks and spots of peak and valley, which represents that larger flat surface areas could be obtained. The results of the XRD tests show that the proposed method could, in general, produce low residual stress values. Further studies of this topic are necessary. The studies demonstrated that the proposed approach is advantageous.

\section{Acknowledgement}

This work has been supported by the Research Grants Council of Hong Kong SAR of China (Project no. HKUST6232/02E).

\section{References}

Choi, H.Z., Lee, S.W. and Jeong, H.D., 2001. A comparison of the cooling effects of compressed cold air and coolant for cylindrical grinding with a CBN wheel, Journal of Materials Processing Technology, 111, pp. 265-268.

Choi, H.Z., Lee, S.W. and Jeong, H.D., 2002. The cooling effects of compressed cold air in cylindrical grinding with alumina and CBN wheels, Journal of Materials Processing Technology, 127, pp. 155-158.

Gao, Y. and Lai, H., 2005. Effects of actively cooled coolant for grinding brittle materials, Key Engineering Materials, 291-292, pp. 233-238.

Gao, Y., Tse, S. and Mak, H., 2003. An active coolant cooling system for applications in surface grinding, Applied Thermal Engineering, 23, pp. 523-537.

Gviniashvili, V.K., Woolley, N.H. and Rowe, W.B., 2004. Useful coolant flowrate in grinding, International Journal of Machine Tools and Manufacture, 44, pp. 629636.

Hryniewwicz, P., Szeri, A.Z. and Jahanmir, S., 2000. Coolant flow in surface grinding with non-porous wheels, International Journal of Mechanical Science, 42, pp. 2347-2367.

Jin, T., Stephenson, D.J. and Rowe, W.B., 2003. Estimation of the convection heat transfer coefficient of coolant within the grinding zone, Proceedings of the Institution of Mechanical Engineers Part B, 217, pp. 397-407.

Nakayama, T., Wakuda, M. and Ota, M., 2004. Ultra-high speed cylindrical grinding using CBN wheel for high efficiency, Key Engineering Materials, 257-258, pp. 273278.

Paul, S. and Chattopadhyay, A.B., 1995. The effect of cryogenic cooling on grinding forces, International Journal of Machine Tools and Manufacture, 36, pp. 63-72.

Paul, S. and Chattopadhyay, A.B., 1995. A study of effects of cryo-cooling in grinding, International Journal of Machine Tools and Manufacture, 35, pp. 109-117.

Paul, S. and Chattopadhyay, A.B., 1996. Determination and control of grinding zone temperature under cryogenic cooling, International Journal of Machine Tools and Manufacture, 36, pp. 491-501. 
Title

Ramesh, K., Huang, H. and Yin, L., 2004. Analytical and experimental investigation of coolant velocity in high speed grinding, International Journal of Machine Tools and Manufacturing, 44, pp. 1069-1076.

Ramesh, K., Yeo, S.H., Zhong, Z.W. and Huang, H., 2003. Ecological grinding with chilled air as coolant, Proceedings of the Institution of Mechanical Engineers Part $B, 217$, pp. 409-419.

Ramesh, K., Yeo, S.H., Zhong, Z.W. and Sim, K.C., 2001. Coolant shoe development for high efficiency grinding, Journal of Materials Processing Technology, 114, pp. 240-245.

Suzuki, K., Qun, H.B., Uematsu, T., Iwai, M. and Kami, T., 2004. Effects of the megasonic floating nozzle on grinding performance for hard materials, Key Engineering Materials, 257-258, pp. 311-314.

Suzuki, K., Qun, H.B., Mishiro, S., Tanaka, K., Imai, T., Sharma, A., Uematsu, T. and Iwai, M., 2003. Grinding performance improvement by a special coolant superimposed with the megasonic vibration, Key Engineering Materials, 238-239, pp. 183-188.

Tsai, H.H. and Hocheng, H., 1998. Investigation of the transient thermal deflection and stresses of the workpiece in surface grinding with the application of a cryogenic magnetic chuck, Journal of Materials Processing Technology, 79, pp. 177-184.

Wang, S.B. and Kou, K.H., 1998. The workpiece temperature, fluid cooling effectiveness and burning threshold of grinding energy in creep feed grinding, Proceedings of the Institution of Mechanical Engineers Part B, 212, pp. 383-391.

Wang, S.B. and Kou, K.H., 1997. Cooling effectiveness of cutting fluid in creep feed grinding, International Communications in Heat and Mass Transfer, 24, pp. 771783. 